\title{
HOBBES Y EL MODELO DE CONVENIO UTILITARIO
}

LUIS VILLORO

INSTTTUTO DE INVESTIGACIONES FILOSÓFICAS

UNIVERSIDAD NACIONAL AUTÓNOMA DE MÉXICO

La filosofía política en la época moderna está dominada por la teoría del convenio o contrato social. Sirve a la vez para explicar el origen de la asociación política y para justificar el poder. Por lo primero intenta dar razón de un hecho histórico, la existencia del Estado, pertenece a un discurso sobre lo que es. Por lo segundo, trata de suministrar un fundamento de legitimidad a un poder, pertenece a un discurso sobre lo que debe ser. ¿Cómo conciliar ambos discursos? La dificultad perdura hasta hoy: reaparece en las doctrinas neocontractualistas contemporáneas. ¿Debemos concebir el convenio social como teoría que explica la existencia del poder político o como doctrina que dicta cómo debería ser el poder legítimo? Esta pregunta es una expresión más del problema central de toda filosofía política, extraña creatura que mira a la vez a la realidad histórica y a la sociedad justa, a lo que es y a lo que debería ser.

Una solución radical al problema sería reducir el discurso del deber ser a términos de un discurso sobre hechos. El Estado legítimo sería resultado entonces de una necesidad fáctica, fundada en la naturaleza humana. El orden normativo se derivaría causalmente de la dinámica de los hechos sociales. La política podría reducirse entonces a una ciencia de hechos. Ese intento podría formularse en un modelo teórico del convenio social que daría razón tanto del origen del Estado como de la obligación moral de obedecerlo. Pues bien, el primero en proponer una versión de ese modelo teórico, aun insuperada, fue Thomas Hobbes.

Revisaremos la teoría hobbesiana del convenio con dos objetivos. 1) Reconstruir, a partir de la versión específica de Hobbes, un modelo general de convenio social, aplicable también a otras teorías semejantes. 2) Tratar de dar respuesta a la cuestión: ¿puede ese modelo de convenio social solucionar el problema de la relación entre los dos discursos de la filosofía política, el del ser y el del deber ser? Con otras palabras: ¿puede una teoría normativa de la sociedad más justa concluirse de una ciencia política sobre la sociedad real? 
Una ciencia de lo político

Hobbes tiene como ideal de ciencia un modelo deductivo, como el de Descartes o el de Spinoza. Tenemos que partir de ciertos elementos primeros, que se presentan a la razón como de suyo evidentes, para llegar por deducción a las consecuencias más complejas. Si este método no está aún muy claro en sus primeros escritos, es patente en el Leviatán. Por otra parte, la ciencia sólo puede considerar hechos reales, materiales; Hobbes es un materialista consecuente. Lo que logró Galileo, al reducir la mecánica de los cuerpos materiales al examen de ciertas fuerzas elementales, para descubrir luego las leyes del movimiento por la relación entre esas fuerzas, lo intentará Hobbes con el cuerpo político. La diferencia es clara: si bien Galileo podía acudir al experimento para confirmar sus hipótesis, Hobbes tiene que atenerse a "experimentos mentales". Pero en ambos casos, los juicios se refieren a relaciones causales entre hechos reales; en ambos casos cualquier situación compleja podrá explicarse al derivarla de los movimientos de fuerzas elementales.

La fuerza primera es el deseo. De él proviene toda moción humana. El deseo está dirigido a la preservación de sí mismo, a la vida, por lo tanto. Vivir es placentero por sí mismo: afán de placer, de goce, aversión al dolor, es nuestro primer móvil. ${ }^{1}$ Si el deseo primario es preservar la vida, su faceta negativa es el temor a la muerte. El miedo es hijo del deseo. Este doble móvil es el principio de todas las acciones humanas. ${ }^{2}$ De allí el afán de poder. Poder como instrumento para asegurar la preservación de la vida, poder para obtener placer en la forma durarera y protegernos contra la muerte violenta. Que hay "una inclinación de la humanidad entera, un perpetuo e incesante afán de poder que sólo cesa con la muerte". ${ }^{3}$

Deseo y miedo son, naturalmente, pasiones individuales. Hobbes parte de los individuos movidos por sus impulsos particulares. Ellos son los "átomos", por así decirlo, sujetos de las fuerzas que originan la estructura social. De las pasiones individuales tendrá que derivarse, con necesidad, la sociedad política. Pero "sociedad política" (commonwealth) implica una relación de varios individuos unidos por una pasión común. El intento de Hobbes consistirá, justamente, en derivar el "bien común" de los deseos individuales.

1 De Homine (en lo sucesivo $D H$ ), cap. II, art. 6, cap. XI, art. 2 y 5; Elements of Law (en lo sucesivo EL), cap. VII, art. 2 y 3; cfr. D.D. Raphael, Hobbes, Morals and Politics, G. Allen and Unwin, Londres, 1977, p. 26.

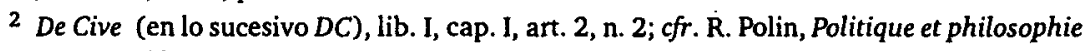
chez Thomas Hobbes, Vrin, Paris, 1977.

3 Leviatán (en lo sucesivo $L$ ), cap. XI (traducción al español: Fondo de Cultura Económica, México, 1940, p. 79). 
Para ello hay que recurrir a un "experimento" mental. Dado el móvil primario de todo hombre, ¿cuál sería la situación de un conjunto de individuos si no hubiera sociedad política? Sólo si imaginamos ese estado, podremos comprender lo que añade el poder político a un agregado de individuos. A esa situación se le ha llamado "estado de naturaleza". Pues bien, es claro que no habiendo en él leyes, ni orden civil, ni prerrogativas sociales, ni instituciones, faltando todo poder que imponga obligaciones a los individuos, en el estado de naturaleza todos los hombres son iguales y libres. Nada en ese estado establece límites a la pasión insaciable de lograr para la propia vida el máximo de placer, nada apacigua el temor de perderlo todo a manos de los otros. Entonces, de manera inevitable, los deseos individuales entrarán en colisión entre ellos. Será un estado de perpetua competencia, en que cada quien tendrá interés en suprimir al otro para obtener poder y preservar su vida. A falta de un poder externo que limite la libertad de cada quien, el campo de las pasiones insaciables es también el del terror ante la violencia ajena. "Así es manifiesto que, durante el tiempo que los hoinures viven sin un poder común que los atemorice, están en esa condición que se llama guerra, y una guerra que es de todos contra todos."4 En ese estado, no puede haber industria, ni civilización, ni ciencia, ni arte, ni asociación alguna, sino "continua cólera y miedo de una muerte violenta, y la vida del hombre es solitaria, pobre, sórdida y breve". 5

Pero hay una diferencia entre el hombre y el animal. Aquél tiene la capacidad de no satisfacer de inmediato su deseo, sino de aplazar su satisfacción para asegurarla; puede incluso contravenir su deseo inmediato para obtener un placer futuro durarero. A la capacidad de calcular la manera de satisfacer el deseo mediante el aplazamiento la llamamos "razón". La razón puede dictarnos la necesidad de renunciar al placer actual e ilimitado con tal de lograr un estado permanente que nos asegure una protección contra la violencia y, por ende, un limitado pero cierto disfrute futuro de la vida. Así, mientras el deseo de la vida impulsa a matar a quien me amenaza, el cálculo racional me indica que la mejor manera de preservar la vida y evitar, de manera permanente, las amenazas ajenas, es llegar a un estado de paz, garante de mi seguridad futura. Por dictado de la razón la satisfacción del deseo se aplaza. .. sólo para asegurar su cumplimiento. ${ }^{6}$

La razón está al servicio de la pasión. Establece las reglas de conducta eficaces para lograr los fines que ésta persigue. Es claro que se trata de una especie peculiar de razón, con caracteres precisos. 1) Obedece a un interés

${ }^{4} L$, cap. XIII (trad. esp., p. 102).

5 Ibid.

6 Hobbes anticipa la distinción de Freud entre "principio de placer" y "principio de realidad". El dictado de la razón sigue este último. 
individual. 2) No tiene sentido preguntar por la racionalidad del objeto mismo del deseo sino de los medios para asegurar su cumplimiento. Es un cálculo para lograr los fines queridos. Corresponde a lo que hoy llamaríamos "racionalidad conforme a fines" (Weber) o "racionalidad instrumental" (Horkheimer).

Pero ese cálculo interesado es realizado por todos. Todos los hombres están dominados por la misma pasión y todos son capaces de tomar las mismas medidas para satisfacerla, aunque sea parcialmente, a largo plazo. Sólo hay una solución para todos: concertarse para evitar vivir con el terror a una muerte violenta. El cálculo interesado conduce al convenio (covenant).

En el estado de naturaleza todos los hombres gozan de una libertad irrec. tricta. En efecto, la libertad es simplemente "la ausencia de impedimentos externos", determinada por lo que no está prohibido por la ley, por el "silencio de la ley". ${ }^{7}$ Donde la libertad es ilimitada, también lo es el derecho, puesto que éste es la "no obligación" de abstenerse de una acción. Donde no hay legislador, no hay ningún obstáculo a la libertad de todos y todos tienen derecho a todo. Justamente por ello todos los hombres son iguales: tienen el mismo derecho y la misma libertad irrestricta. Nadie tiene prohibido matar al otro y utilizar todos los medios a su alcance para preservar la propia vida. Todo hombre, en estado de naturaleza, puede realizar el supremo acto de poder: quitar la vida a otro hombre. ${ }^{8}$

Notemos que, en este contexto, "derecho" no implica "deber". Porque todo deber deriva de un mandato. Como en el estado de naturaleza aún no hay'mandatos, "derecho" no debe tomarse en un sentido jurídico; no hay aún leyes que otorguen "derechos" y prescriban "deberes". "Derecho" es sólo "ausencia de impedimento", "silencio de la ley". Equivale, pues, a "poder", como más tarde lo vió Locke. Sólo el legislador podrá convertir ese poder en un "derecho" en sentido jurídico. Al hacerlo, establecerá límites al poder individual en beneficio del interés general.

La única forma racional de lograr la paz es pues que todos convengan en renunciar a su derecho irrestricto, en favor de un poder común que lo limite. Cada quien aceptaría el siguiente compromiso: "Autorizo y transfiero mi derecho de gobernarme a mí mismo a este hombre o asamblea de hombres, con la condición de que vosotros autoricéis y transfiráis todas vuestras acciones de la misma manera." Con este acto colectivo, de una multitud se constituye una sociedad política. "Hecho esto —continúa Hobbes - una multitud así unida en una persona es llamada una sociedad política (commonwealth), en latín civitas. Ésta es la generación de ese gran Leviatán, o mejor dicho,

7 L, cap. XIV (trad. esp., p. 179).

8 Cfr. R. Polin, op. cit., p. 135. 
de ese dios mortal a quien debemos, bajo el Dios inmortal, nuestra paz y nuestra defensa." 9

Notemos varios puntos:

1. La asociación entre individuos se constituye en el convenio. No existe antes. La idea clásica del pacto social, en Santo Tomás, por ejemplo, o en sus seguidores: Hooker, Suárez, etc., partía de una sociedad ya existente, producto de una larga evolución histórica. El individuo nacía ya en el seno de esa sociedad. La sumisión a un poder soberano se realizaba sobre el supuesto de esa previa asociación. De allí la necesidad de distinguir entre el pactum conjunctionis, que establece la asociación, y el pactum subjetionis, por el que se someten los individuos ya asociados al poder de un soberano. El segundo sólo se establece sobre una sociedad previamente constituida por las relaciones históricas reales. Hobbes, en cambio, inaugura una visión distinta: el pactum cojunctionis y el pactum subjetionis son uno y el mismo. El acto de sujeción libre a un soberano constituye la sociedad política. Luego, se concibe la sociedad como resultante del acuerdo libre entre individuos. Lo único que precede a la sociedad política es un conjunto de individuos aislados. Estamos frente a una expresión del "individualismo" propio del pensamiento moderno.

2. El convenio crea una persona colectiva, artificial. ¿Cómo lograr, en efecto, la unidad a partir de los deseos encontrados de todos? Sólo por un representante en el que se delegue la voluntad de todos. "Soberano" llamamos a ese representante y su voluntad se convierte en la voluntad de todos. El soberano es el poder supremo sobre los ciudadanos, no sometido a las leyes (legibus solutus), según la fórmula de Jean Bodin. ${ }^{10}$ En efecto, toda ley es un mandato ordenado por el sujeto facultado para ello, al cual otros sujetos están obligados a obedecer. El mandato es una relación asimétrica: supone un agente que ordena la realización u omisión de una conducta y otro que ha de realizar esa conducta. El agente que ordena puede estar a su vez sometido a las órdenes de otro agente superior y así sucesivamente. Pero la cadena ha de detenerse en un primer agente que ya no esté, él mismo, obligado por un mandato. Ése es el soberano. El soberano no puede estar sujeto a la ley puesto que es la fuente última de toda ley; si lo estuviera, el promulgador de esa ley sería el auténtico soberano.

El convenio se efectúa entre los miembros de la sociedad, pero no entre éstos y el soberano. Puesto que el soberano no ha participado en el convenio, no está obligado por él. Conserva su libertad frente a toda ley que

9 , cap. XVII (trad. esp., p. 141).

10 De Republica libri sex, París, 1584, lib. I, cap. 8. Cfr. Victor Flores Olea, Ensayo sobre la soberanía del Estado, UNAM, 1969, cap. II. 
pudiese limitarla. Como observará más tarde Locke, en Hobbes el soberano permanece en "estado de naturaleza" para que todos los pactantes puedan acceder al estado civil. El pacto social delega todo el poder de los pactantes en una persona o asamblea de personas, para que ésta imponga la paz. Sólo si hay soberano hay sociedad política, hay ordenamientos, justicia, limitación de derechos, seguridad pública, propiedad; sólo entonces hay obligaciones porque sólo entonces hay ley. Así se logra lo que cada quien anhelaba: desterrar el terror a la muerte violenta y preservar la propia vida.

3. En el convenio, cada quien renuncia a su derecho, con la condición de que los demás también lo hagan. Cada quien busca exclusivamente su propio beneficio, pero, al buscarlo, coincide con los demás en un interés común. El bien común no se busca por sí mismo; resulta, de hecho, de la coincidencia de intereses particulares guiados por el cálculo racional. Pero entonces, cada quien sigue adherido al convenio en la medida en que responda a su interés particular. Cada quien podrá engañar al otro y faltar a lo convenido si con ello satisface mejor su deseo de vida. En verdad, lo que mejor convendría a su interés sería una situación en que todos los demás se sujetaran al convenio salvo él. Y éste es un cálculo que todos pueden hacer. Sólo por miedo, cada quien se atiene al convenio, pero si su razón le dictare que podría desobedecerlo sin peligro, mientras los demás lo acatan, lo más racional sería faltar al convenio. Ante esa situación, es menester una garantía de que nadie fallará al convenio por interés propio y en perjuicio de los demás. De ahí que el soberano, que no es parte del convenio, sea el que monopolice la fuerza de todos, para hacer respetar el convenio. Un soberano ajeno a los pactantes es necesario, en la medida en que éstos están dirigidos exclusivamente por su interés particular y no identifican éste con el bien común.

Hobbes ha intentado explicar el origen de la sociedad política mediante una serie de relaciones causales que parten de fuerzas elementales y llegan hasta sus consecuencias, sin acudir a ningún elemento externo a esas fuerzas. El Estado no existe porque cumpla con algún "deber ser", o realice algún valor que no sea el efecto de los propios impulsos vitales. De manera parecida a la filosofía antigua, en Hobbes el Estado se funda en la naturaleza. Pero ahora ha cambiado el concepto de "naturaleza". Ya no tiene un sentido teleológico sino determinista. El bien común no se realiza porque a él tienda la naturaleza como a su propio fin, sino porque satisface la pasión natural más fuerte del hombre. La pasión reemplaza al telos, señala Leo Strauss. ${ }^{11}$ 
La sociedad política es el medio que encuentra la razón para asegurar la realización del deseo individual. Es el producto de una mecánica de la pasión y del cálculo racional. Sobre el deseo se ejerce una forma específica de racionalidad, cuya función es que el deseo sea real y no se frustre; ella descubre las cadenas causales entre hechos y las utiliza como medios conducentes para realizar el objeto del interés individual: cálculo utilitario, razón instrumental. La política trata así de relaciones causales entre hechos. Puede haber pues una ciencia de la política. ¿Qué pasa con la ética?

\section{Una ética del egoísmo}

Bueno es simplemente el objeto de la pasión. "Cualquier cosa objeto del apetito o deseo de un hombre es lo que, por su parte, llama bueno, y cualquier objeto de su odio o aversión, malo." 12 La ética estaría constituida por las reglas racionales que prescriben cómo lograr el objeto del deseo; luego, podría reducirse a una ciencia de hechos. En efecto, la ciencia - piensa Hobbes - es el conocimiento de las consecuencias; la ética, una parte de la "filosofía natural", sería la ciencia de las "consecuencias de las pasiones del hombre". ${ }^{13}$ El discurso que podemos llamar "valorativo" quedaría así reducido a un discurso "explicativo"; el lenguaje sobre bienes y deberes, explicado en enunciados sobre hechos: deseos, medios para cumplir los deseos.

Antes de la creación del Estado, no hay ley que limite la libertad de cualquier hombre. Todos tienen derecho a todo. Por lo tanto, nada puede en rigor llamarse justo o injusto. "Hay también una consecuencia de esta guerra de todos contra todos: que nada puede ser injusto. Las nociones de correcto e incorrecto, de justo e injusto no tienen lugar ahí. Donde no hay poder común no hay ley; donde no hay ley, no hay injusticia."14 No es que el Estado de naturaleza sea justo, es que carece de sentido aplicarle tanto ese término como su contrario, porque ambos presuponen, para adquirir significado, un orden normativo.

La sociedad política no puede, por lo tanto, fundarse en un orden anterior de derecho, como piensan los jusnaturalistas clásicos, sino que, al contrario, todo orden jurídico se funda en la sociedad política. "Antes de que los nombres 'justo' e 'injusto' puedan tener lugar, debe de haber algún poder concebido para compelir a todos los hombres al cumplimiento de sus

$12 L$, cap. 6 (trad. esp., p. 42).

$13 L$, cap. IX (trad. esp., p. 73).

$14 L$, cap. XIII (trad. esp., p. 104). 
convenios, por el terror de algún castigo mayor que el beneficio que esperan al romperlos." 15

No puede haber obligación donde no hay contrato. El mismo acuerdo que crea el Estado establece las condiciones para que algo pueda llamarse justo o injusto. Por otra parte, ese acuerdo establece el poder común que garantiza el cumplimiento de lo acordado por los pactantes. El mismo convenio es origen del Estado y fuente de la ley. La ley establece qué es lo justo y el soberano fuerza su realización. Dado que la ley emana de la voluntad común expresada por el soberano, la sumisión del ciudadano a la ley es cumplimiento de la voluntad común. El mismo acto que da lugar a la soberanía es origen de la obligación.

El orden legal derivado del convenio es el único que puede establecer límites a los derechos de cada quien y, por ende, delimitar lo justo de lo injusto. Con la ley nace la obligación.

Una pregunta fundamental de la filosofía política y de la filosofía del derecho es: ¿por qué obedecer? ¿Por qué estoy obligado a cumplir la ley? La primera respuesta de Hobbes sería: por miedo al castigo; luego, si puedo eludir el castigo, no me creo obligado. La segunda podría ser: porque obedecer la ley me garantiza la permanencia del convenio y, por ende, la seguridad que busco; aunque ahora pueda perjudicarme, a la larga me beneficia. Pero habría una tercera respuesta: estoy obligado simplemente porque así lo he convenido. El contrato me liga. La sujeción al soberano y la obediencia a la ley promulgada por él es también una obligación moral, por ser consecuencia de un convenio al que cada quien se ha comprometido libremente. Ese convenio es resultante de la coincidencia de la voluntad de todos, mantenerlo expresa el interés general en el que pueden coincidir los intereses particulares.

La política no se funda pues en la moral, la moral deriva del acto político por excelencia. La acción política no debe, por lo tanto, obedecer a normas previas a ella; por lo contrario, la ley emanada de la constitución de la sociedad política establece cuáles deben ser las normas morales. Si esto es así, no podríamos hablar propiamente de otras leyes que las promulgadas por el soberano. Sin embargo, Hobbes habla de "leyes naturales". ¿No cae en una contradicción?

Al hablar de "leyes naturales", Hobbes hace una concesión lingüística a una concepción admitida en su época, pero les da, en realidad, una connotación tal, que es incompatible con la concepción tradicional. D.D. Raphael y R. Polin han ofrecido una interpretación convincente de la doctrina de las leyes naturales en Hobbes, que seguimos, en lo esencial. ${ }^{16}$

$15 L$, cap. XV (trad. esp., p. 118).

16 D.D. Raphael, op. cit., cap. V; R. Polin, op. cit., cap. VIII. 
El derecho natural tenía por función principal explicar la oposición entre las leyes positivas, dictadas por un soberano, que podían ser moralmente injustas, y las normas éticas, de validez universal, fundadas en la voluntad de Dios, en la naturaleza o en la "razón". Sólo así se podía justificar la impugnación de las leyes positivas por razones morales. En Hobbes, en cambio, no puede existir esa dualidad de órdenes legales.

En primer lugar, no hay que confundir "ley" y "derecho". Ya Jean Bodin habia distinguido esos conceptos: "Pluribus distat lex a jure. Ius est [...] ars boni et æqui. Lex quodam ad majestatem imperandum pertinet."17 "Ley" es un mandato de quien tiene el "imperio", el soberano. "Derecho" (ius), en cambio, remite a un orden natural, de lo "bueno" y "justo", anterior e independiente de la constitución del "imperio". Al igual que Bodin y en oposición a Richard Hooker y a Edward Coke, con quienes polemiza, Hobbes separa "ley" y "derecho". Ley, por definición, implica mandato. "Hazlo porque tengo derecho a obligarte, o hazlo porque yo digo 'hazlo' " es la ley. ${ }^{18}$ La ley no describe un comportamiento de los hechos, como en la filosofía natural, sino prescribe una relación entre hombres. En De Cive la define: "la ley es el mandato de una persona cuya decisión constituye una razón suficiente para obedecerla".19 "Derecho" (ius) no puede usarse en Hobbes con el mismo sentido que en Bodin, puesto que para él no existe un orden de "lo bueno y lo justo" anterior al convenio. Lo propio de la ley es obligar a una acción, lo propio del derecho es estar libre respecto de una acción. La naturaleza del derecho es permitir ejercer la libertad. "El derecho consiste en la libertad de hacer o de omitir, mientras que la ley determina y ata a una de esas dos posibilidades: así es que la ley y el derecho difieren tanto como la obligación y la libertad, que referidas a uno y el mismo asunto son inconsistentes." 20

En el estado de naturaleza el derecho es ilimitado, puesto que no hay ley que lo coarte; hay "un derecho de cualquier hombre a cualquier cosa, un derecho de todos a todo". ${ }^{21}$ En ese estado, no habría pues lugar para una "ley natural" frente a leyes civiles, pues donde todos son absolutamente libres no hay un mandato que limite esa libertad. "El derecho natural, que los escritores llaman comúnmente ius naturale, es la libertad que tiene cada hombre de usar su propio poder como él lo quiera para la preservación de su propia naturaleza, es decir, de su propia vida, y en consecuencia de hacer cualesquiera cosas que, según su propio juicio y razón, conciba ser

17 Cit. V. Flores Olea, op. cit., p. 23.

18 EL, parte II, cap. II, art. 4.

$19 D C$, cap. XIV, art. 4 ; cfr. $L$, cap. XXXI.

$20 L$, cap. XIV (trad. esp., p. 106).

21 EL, cap. XIV, art. 10. 
los medios más apropiados para ello."22 Hobbes tiene una posición más radical que la de Bodin. Este último, si bien considera el derecho ligado a la libertad y distinto de la ley, sigue refiriéndolo a un "orden natural" de carácter moral, mientras que para Hobbes es sólo un poder del hombre, no sujeto a orden alguno.

Por lo tanto, no puede hablar de "leyes naturales" en su sentido habitual. En efecto, el estado de naturaleza carece de la condición que define la ley: carece de mandato que obligue. ${ }^{23}$ Lo que llamamos "ley", en ese contexto, no puede interpretarse entonces más que como un conjunto de reglas para preservar la vida, dictadas por un cálculo racional. El impulso inmediato lleva a cada quien a la guerrra contra los demás; es la razón la que nos persuade que para lograr preservar la vida en forma duradera el mejor medio es la paz. Establece así un primer precepto o regla general, que Hobbes sigue llamando "ley natural". Dice así: "Cada quien debe buscar la paz, mientras tenga esperanza de lograrla, y, si no puede obtenerla, debe buscar y usar todos los medios y ventajas de la guerra." ${ }^{24}$ Es claro que la obligación de buscar la paz no es incondicionada. Sólo se prescribe si es un medio adecuado para preservar la vida, de lo contrario habrá que buscar el mismo fin por la prolongación de la violencia. Se trata pues de una regla que establece los medios preferibles para lograr un fin deseado. "Una ley de la naturaleza -escribe Hobbes- es un precepto o regla general, descubierto por la razón, por el que se le prohíbe a un hombre hacer lo que es destructor de su vida, o dejar de utilizar los medios de preservarla y omitir lo que él piensa que sería mejor para preservarla." 25

$\mathrm{Si}$ examinamos con cuidado las 18 "leyes naturales" enumeradas por Hobbes, después de aquella inicial, veremos que se refieren a medios para lograr lo prescrito por la primera ley. Puesto que el medio para la paz es el convenio social, algunas (leyes 2,3 y 10 ) se refieren justamente a las características que debe tener un convenio para ser efectivo. Las otras "leyes" se refieren a relaciones entre hombres que ya suponen la sociedad política, que no se dan, por lo tanto, en estado de naturaleza. Regulan la manera como el convenio social puede efectivamente conducir a una paz duradera y evitar el retorno al estado de guerra; por ejemplo: perdonar las ofensas (ley 6), reconocer a los otros como iguales (ley 9), juzgar con equidad y sin

$22 L$, cap. XIV (trad. esp., p. 106).

23 Sólo podría hablar propiamente de "leyes", en ese estado, si se consideran promulgadas por un legislador universal: Dios. Pero, aunque Hobbes evoca esta hipótesis (cap. XV), no la considera en su sistema, por no ser científica.

$24 L$, cap. XIV (trad. esp., p. 107).

$25 L$, cap. XIV (trad. esp., p. 106). 
parcialidad (leyes 11,17 y 18), o —entrando en mayores detalles-proveer salvoconductos (ley 15). En suma, las leyes naturales dictan las "maneras de hacer que el convenio sea durarero, afiance la paz y conserve la vida del hombre en medio de las multitudes". ${ }^{26}$

Las leyes naturales expresarían una especie de imperativo hipotético de la razón: establecerían las reglas que tenemos que seguir si queremos sobrevivir en medio de los otros hombres. Si no se dan las condiciones para la paz, porque, por ejemplo, los demás no actúen conforme al convenio, no obligan a cumplirlas; pues en ese caso, hacerlo no conduciría a la preservación de la vida. ${ }^{27}$

En realidad, el incumplimiento de una "ley natural" se asemeja más a una conducta incongruente en la práctica que al quebrantamiento de una norma. En efecto, al realizar el convenio me comprometo a actuar de manera que sea efectivo, por lo tanto, a seguir las medidas racionales que aseguren su cumplimiento. No hacerlo sería actuar inconsecuentemente, equivaldría a lo que podríamos llamar una "contradicción práctica". Sería "algo así como lo que en las disputas de los escolásticos se llama absurdo, contradecir lo que se mantuvo en un principio: así en el mundo se llama injusticia e injuria deshacer voluntariamente lo que en un principio se había hecho voluntariamente".28

La distinción entre ley natural y ley positiva permitía aceptar normas éticas objetivas que podían diferir de los mandatos de un poder efectivo. Hobbes rompe con esa dualidad. Sólo existe un orden normativo: el que deriva del soberano, estatuido por el convenio. La ética es un elemento necesario en la cadena que conduce del deseo de vivir y el terror a la muerte, al mantenimiento de la paz, garantizada por el Estado. La tensión entre ética y política desaparece, porque la primera es un elemento de la segunda.

La ética que deriva del convenio pertenece pues a la "mecánica de las pasiones". En efecto, no postula valores ni prescribe normas independientes de la sociedad real, a la que ésta debiera conformarse. Sus juicios prescriben los medios adecuados para alcanzar el cumplimiento de la pasión fundamental del hombre. La ética está al servicio de la satisfacción de un interés personal. Es una ética del egoísmo.

26 L, cap. XV (trad. esp., p. 131).

$27 L$, cap. XV.

28 L, cap. XIV (trad. esp., p. 108). En este sentido podriamos interpretar lo que parecería una contradicción de Hobbes: denominar "inmutables" y "eternas" esas reglas de la razón. En realidad, el texto muestra que lo que quiere decir Hobbes es que son "verdades a priori", no falsificables por la experiencia, "pues no puede ser que la guerra preserve la vida y la paz la destruya". 
Un modelo de convenio social

La teoría de Hobbes puede verse como un ejemplar de un modelo general de convenio social, que podría presentarse en otras muchas formulaciones. De hecho el mismo modelo puede reconocerse en varios autores posteriores. Se trataría de un tipo de convenio que podríamos llamar "utilitario", por tratar de explicar y justificar la sociedad política por su utilidad para el individuo. Trataré de resumir en unas cuantas características los rasgos de ese modelo explicativo:

1. Todo sujeto está movido por un interés personal, egoísta. La razón está al servicio de ese interés. Cumplirá su función al satisfacer lo mejor posible el interés individual al menor costo. Ahora diríamos que la razón se dirigirá por el principio de maximizar el propio beneficio y minimizar el costo personal.

2. La sociedad política es el resultado del convenio entre individuos igualmente guiados por un cálculo racional interesado. El convenio debe satisfacer parcialmente a todos. Como cada quien intenta lograrlo con el máximo de beneficio para él y el mínimo costo, el convenio es resultado de una concesión recíproca entre los contrayentes. Cada quien limita su libertad, sus "derechos", con tal de obtener un beneficio. El consenso que expresa el convenio es resultado de una negociación en que cada quien pretende hacer valer su interés particular.

3. El convenio se logra al obtener consenso sobre un "núcleo" de valores aceptado por todos. Éste es un "bien común". Vale para todos. Los intereses particulares no lo ponen en cuestión; pero no porque esté por encima de ellos, sino porque es la manera de realizar el interés particular. Así, de la coincidencia de los intereses particulares surge, de hecho, un interés común. De la posición egoísta de cada quien surge un bien general. Pero el bien general no ha sido querido por él mismo antes del convenio; antes del convenio, cada quien desea exclusivamente su bien particular. El bien general es aceptado, después del convenio, sólo por ser un medio para satisfacer aquel interés particular. Por lo tanto, cada quien lo acepta sólo en tanto cumpla y no dañe el interés individual.

4. El Estado (o el "soberano") es el garante del cumplimiento del convenio. Como cada individuo acepta el convenio como un medio para satisfacer su interés particular, podría faltar a él si no lo satisface. Conviene en respetar al otro sólo porque ello es necesario para lograr su fin personal. Si pudiera hacerlo sin perjuicio propio, cada quien suprimiría al otro. Por ello es necesario que el Estado imponga por la fuerza el bien común convenido. El Estado tiene por función el ejercicio de la coacción para hacer cumplir el bien común. 
5. En todos los campos que no conciernen al "núcleo" de valores aceptado por todos, permanece el conflicto entre los intereses particulares. Puesto que cada quien sigue viendo a los otros como medios para realizar su interés particular, cada quien intentará aventajar al otro en beneficio propio. La constitución de la sociedad política no elimina el conflicto en la sociedad civil. Como bien vio Hegel, en la sociedad civil, es decir, en el conjunto de actividades e instituciones que no caen en el control impositivo del Estado, permanece la "lucha de todos contra todos".

6. El soberano es la fuente última del orden normativo. La obligación de obedecerlo deriva del convenio que lo instituyó como fuente legítima de derecho. El orden normativo en la sociedad política se identifica con el orden jurídico, promulgado por el soberano.

7. El orden normativo deriva, en último término, de la voluntad de los sujetos sometidos a él, puesto que ellos fueron los agentes del convenio. Sin embargo, cada quien considera la obligación de obedecer condicionada a la satisfacción de su interés particular, puesto que sólo aceptó el convenio como medio de realizarlo. La validez de la norma no es incondicionada, por ello debe ser impuesta por coacción.

Esas siete características describen el esquema más general de un modelo de explicación que puede revestirse de rasgos distintivos diferentes en variadas versiones. La teoría de Hobbes puede verse como un caso particular de ese modelo. Las siete características que hemos enunciado se presentan en él con rasgos particulares. Para entender mejo: la generalidad del modelo, destacaré ahora algunos de los rasgos propio: de la teoría hobbesiana, que no son esenciales al modelo general y que, por lo tanto, podrían variar sin alterar el modelo.

1. (Respecto de las características 1,2, y 3.) El "bien común" resultante del convenio es, para Hobbes, la preservación de la vida individual mediante la instauración de la paz. Pero podría ser más amplio. Podrían los pactantes considerar que la vida no puede, en realidad, mantenerse sin el disfrute de los bienes de propiedad individual o sin el resguardo de una libertad personal para usar de ellos. Entonces, el "núcleo" de valores comunes, que podría ser objeto de un consenso interesado, sería más complejo, hasta llegar eventualmente a comprender todos los "derechos" o valores individuales de la concepción liberal.

Esencial al modelo no es el contenido del núcleo pactado como bien común, sino el hecho de que ese "núcleo" se determina por un acuerdo entre todos, en el que cada quien está guiado por su interés particular. Así, el límite del núcleo de valores comunes convenidos coincidiría con los 
límites del compromiso efectivo al que lleguen los contrayentes, en respetar cada quien los intereses ajenos en beneficio propio.

El contenido del núcleo convenido variará también según sea el móvil egoista que impulse al convenio. En Hobbes es el más elemental y profundo: el deseo de vivir y el miedo a una muerte violenta. Por eso el "bien común" logrado en el convenio se restringe a la preservación de la vida y al mantenimiento de la paz social. Pero el móvil que conduce al convenio puede ser más complejo. Podría ser el deseo de libertad individual para disfrutar de los propios bienes (como en Locke) o inclusive la persecución por cada quien de su felicidad personal (como en Jefferson). De acuerdo con la pasión que conduzca al convenio será el núcleo de valores pactado. Podrá así llegar a abarcar tantos "derechos individuales" comunes a todos los pactantes como satisfagan esos deseos particulares que originaron el convenio.

2. (Respecto a la característica 4.) En Hobbes la forma de gobierno derivada del convenio puede variar. Los contrayentes pueden convenir en designar como soberano a un individuo, a un grupo de individuos o a una asamblea representativa de los ciudadanos. Según la elección que hagan, estatuirán un gobierno monárquico, oligárquico o democrático. La teoría hobbesiana puede aplicarse a cualquiera de esos tipos de gobierno. Sin embargo, Hobbes es partidario de una monarquía absoluta. Pero esa opción requiere de una argumentación específica, distinta de la que concluye en la necesidad del convenio utilitario. El modelo subsiste si se sostienen, por ejemplo, las ventajas de la democracia representativa para mantener la paz y preservar la vida personal de los contrayentes. De hecho, según sea el móvil que conduce al convenio, se tenderá a argumentar en favor de una u otra forma de gobierno como la más apta para cumplirlo. Si el móvil es exclusivamente la preservación de la vida frente a las amenazas ajenas, el gobierno absoluto será probablemente el medio más apto para preservarla, como argumenta Hobbes; en cambio, si el fin buscado es la realización personal en la libertad de disfrutar de los propios bienes, el gobierno más apto para ello podría ser una democracia representativa, como sostendrán los liberales discípulos de Locke. El modelo general utilitario es neutro frente a esa opción. En nuestros tiempos, puede ser utilizado para explicar y justificar tanto un régimen dictatorial, que tendría por fin mantener el orden y desterrar la violencia intestina, como un régimen democrático, destinado a preservar la libertad y la propiedad individuales. Lo esencial del modelo es que el gobierno sea el resultado efectivo de un convenio negociado entre los intereses particulares.

3. (Respecto a la característica 5.) Hobbes reduce la "lucha de todos contra todos" al estado de naturaleza. El convenio establecería un corte 
con ese estado y lo reemplazaría por un estado político. Pero puesto que la paz resultante del convenio sólo se instaura por la coacción ejercida por el soberano y sólo tiene por fin la preservación de la vida, la oposición de los intereses particulares continuará allí donde la fuerza del Estado no alcance y dónde no sólo esté en juego la preservación de la vida. La lucha de todos contra todos describe, en realidad, la situación de un conjunto de sujetos fuera del imperio del Estado. Corresponde a la sociedad civil. Por lo tanto, el convenio no la elimina, sólo la limita y restringe.

4. (Respecto a las características 6 y 7.) Para Hobbes la forma de obligación que dimana del convenio es la de una ética utilitaria. La denominé "ética del egoísmo". Pero las normas de esa ética, como vimos, se confunden, en realidad, con las del orden jurídico promulgado por el soberano. Esa confusión es propia de la interpretación de Hobbes y de cualquier formalismo jurídico, pero no es esencial al modelo. Otros autores podrían distinguir entre un orden jurídico y un orden moral, sin negar el modelo de convenio utilitario, con tal de mantener que toda obligación política colectiva se fun$\mathrm{da}$ en la voluntad de quien tiene derecho de ordenar, es decir, el soberano. Lo característico del convenio utilitario es que la obligación se basa en el mandato de la ley promulgada por el soberano legítimo. Si se le opone otra forma de obligación, por ejemplo una obligación moral o religiosa, ésta tendrá que presentarse como una obligación privada, ajena a la obligación colectiva que se rige en el orden político establecido.

\section{Límites del convenio utilitario}

Ahora tenemos más elementos para intentar responder a la pregunta: ¿en qué medida el modelo utilitario de convenio puede resolver la relación entre la sociedad política existente y la sociedad justa? ¿Hasta qué punto resuelve el problema de la relación entre el discurso político de hechos y el del deber ser?

El modelo utilitario tiene una enorme virtud teórica. Da una respuesta al problema de la motivación real que llevaría a constituir un orden político. Éste puede explicarse porque responde a intereses reales de los hombres. Así, el orden normativo queda fundado en el cálculo racional que da satisfacción a las pasiones efectivas que mueven a los hombres. El hiato que separa el orden del deber ser del orden del ser queda franqueado por la razón utilitaria al servicio de los intereses particulares. Desde Hobbes será muy difícil sostener que el orden político no acuda, en último término, para justificar su legitimidad, a la satisfación de un interés real de individuos o grupos humanos.

No obstante, el modelo utilitario se topa con serias limitaciones. Señalaré las tres que me parecen más importantes. 
1. El modelo parte de la idea de móviles humanos exclusivamente egoístas. Puede tratarse del deseo elemental de mantenerse en vida o de deseos más complejos de realización personal, pero siempre se tratará de un interés dirigido al beneficio propio. Los intereses de los otros sujetos sólo pueden verse, desde esta perspectiva, como factores que difieren y pueden oponerse al propio interés; hay pues que utilizarlos de tal manera que se neutralicen o que se conviertan en medios que colaboren a la realización del propio interés. En consecuencia, la racionalidad conducente al convenio es siempre un cálculo interesado, que no tiene por fin satisfacer el interés de todos por igual, mas que sí es un medio para lograr el mayor beneficio para cada agente. Las demás características del convenio se derivan de ese supuesto inicial.

Pero, ¿en qué se basa ese supuesto? Proviene de una lectura de la naturaleza humana. No es deducido de un saber científico previo, es resultado de experiencias vividas. La visión del hombre como una naturaleza rapaz, egoísta, que tiene Hobbes, es anterior a cualquier ciencia deductiva, es un dato primario, al igual que la naturaleza benévola y amigable de otros autores. El modelo de convenio que aceptemos dependerá entonces de lo que he llamado en otra parte un "conocimiento personal".

¿Qué pasaría si en la base del convenio supusiéramos, ya no una pasión egoísta, sino también "deseos objetales", dirigidos tanto a la realización de sí mismo como de los otros, tales como compasión, simpatía, benevolencia, altruísmo, etc.? La naturaleza del convenio cambiaría. Cada quien no lo vería ya desde su particular punto de vista sino desde el punto de vista de todos por igual. Pero, ¿es eso factible?

2. El modelo utilitario de convenio sólo puede explicar las actitudes de disidencia o rebelión contra el poder establecido como oposición de un interés particular contra el bien común convenido por todos. No puede justificar el derecho a la disidencia o a la rebelión por considerar el orden establecido injusto. Para ese modelo carece de sentido impugnar el "bien común" convenido de hecho, a nombre de valores sociales superiores, puesto que todo orden de valores sociales deriva del convenio mismo. La legitimidad de cualquier rebeldía contra el orden resultante del convenio sólo puede invocar el convenio mismo, porque se considere que aquel orden no realice adecuadamente el "núcleo" de valores convenido. Así, se podría impugnar una forma de gobierno o una legislación particular por no corresponder a los términos del convenio básico. Lo que no tiene explicación posible es una rebeldía que se fundara en razones morales, a partir de las cuales se juzgara injusto el convenio mismo. Para ello habría que suponer un orden normativo independiente del convenio, a partir del cual enjuiciar éste, y un 
"bien común" que podría diferir del establecido por la convergencia de los intereses particulares.

Dado que la obligación de obediencia se basa, en último término, en el orden promulgado por el soberano, no cabe la posibilidad de plantear una oposición al orden jurídico a nombre de otro orden normativo considerado superior. La ética tiene entonces que reducirse al orden legal promulgado, y en este punto Hobbes fue perfectamente coherente. No tiene pues ningún sentido una apelación a una "justicia" fuera de lo establecido por ese orden. Pero entonces el convenio utilitario no da razón de la rebelión por razones de la razón práctica.

3. Puesto que el modelo utilitario de convenio no elimina la lucha de los intereses particulares en la sociedad civil y reduce el consenso al resultado logrado por el cálculo de intereses egoístas, el "bien común" que obliga a todos responde en cada momento a la situación de fuerza de los distintos intereses particulares. Expresa lo que, en la situación en que se realiza el convenio, resulta aceptable o conveniente para todos, de acuerdo con las posibilidades que tenga cada quien de hacer prevalecer su particular interés. Puesto que, para llegar al convenio, cada quien se atiene a su interés particular, el convenio es resultado del choque y negociación entre esos intereses particulares. Pero en la negociación no se excluye una posición de fuerza. En efecto, entre las partes contratantes puede existir un desequilibrio de fuerzas. El más fuerte logrará una mayor ventaja en el convenio. El núcleo de valores comunes convenido y el orden de derecho que emane del convenio corresponderá, por lo tanto, de manera preponderante, a los intereses con mayor capacidad real de convencimiento. El "bien común" resultante consagrará entonces una situación de poder.

La posibilidad de impugnar un orden político, por juzgar que corresponde a una situación real de poder y no a un orden justo, queda fuera de un modelo utilitario de convenio. Ello obliga a poner de nuevo en duda que el bien general pueda derivarse de la contraposición y consenso de intereses particulares. Pero entonces parecería que, después de todo, el orden del deber ser no podría deducirse del orden fáctico. ¿Habría entonces que plantear otro modelo de convenio? 